Journal Club

Editor's Note: These short reviews of recent JNeurosci articles, written exclusively by students or postdoctoral fellows, summarize the important findings of the paper and provide additional insight and commentary. If the authors of the highlighted article have written a response to the Journal Club, the response can be found by viewing the Journal Club at www.jneurosci.org. For more information on the format, review process, and purpose of Journal Club articles, please see http://jneurosci.org/content/ preparing-manuscript\#journalclub.

\title{
Expression of Bona Fide Epithelial Stem Cell Marker in Postmitotic Olfactory Bulb Neurons Suggest Novel Roles for Wnt Signaling in the Brain
}

\author{
(C)Camila M. Barrios-Camacho \\ Department of Developmental, Molecular, and Chemical Biology, School of Medicine, and Program in Neuroscience, Sackler School of Graduate Biomedical \\ Sciences, Tufts University, Boston, Massachusetts 02111 \\ Review of Yu et al.
}

The study of neural stem cell biology is inherently tied to broader questions regarding cell identity. With the rise of single-cell technologies, we can characterize neural stem cell niches with greater resolution and these tools have revealed previously undiscovered molecular properties (Artegiani et al., 2017). This is of clinical importance because, if subpopulations can be extracted from stem cell niches, then their manipulation might result in more homogenous - and desirable-therapeutic responses. Consistent with the goal of precisely annotating stem cell populations, a major tenet of stem cell biology is the identification of stem cell markers that allow researchers to investigate how stem cells self-renew, maintain dormancy, or pursue their respective lineages.

Bona fide stem cell markers are those that reliably and robustly label stem cells across a large set of tissues or cellular populations. For example, CD133 is a glycoprotein found in neuronal and en-

Received Nov. 19, 2017; revised Jan. 27, 2018; accepted Feb. 9, 2018. Correspondence should be addressed to Camila M. Barrios-Camacho, Department of Developmental, Molecular, and Chemical Biology, School of Medicine, and Program in Neuroscience, Sackler School of Graduate Biomedical Sciences, Tufts University, 136 Harrison Avenue, Boston, MA 02111.E-mail: camila.barrios_camacho@tufts.edu.

DOI:10.1523/JNEUROSCI.3295-17.2018

Copyright $\odot 2018$ the authors $\quad 0270-6474 / 18 / 382920-03 \$ 15.00 / 0$ dothelial progenitors, glioblastoma stem cells, cancer stem cells, and others (Sun et al., 2009; Li, 2013). Although they are unusual and rare, mature cell types are known to express stem cell markers (Sei et al., 2011; Chiva-Blanch et al., 2016); however, the biological meaning underlying this phenomenon is not understood.

Yu et al. (2017) explore a puzzling and novel role for Lgr5, a canonical stem cell marker that labels a wide array of epithelial stem cell populations (Barker et al., 2010; Koo and Clevers, 2014). Lgr5 is a G-proteincoupled receptor and member of the Wnt-signaling family; Lgr5 potentiates Wnt signaling by binding R-spondins and preventing the endocytosis of the Wnt signaling receptor complex (de Lau et al., 2014). Lgr5 has been studied extensively in the context of epithelial stem cell niches; however, newer work has begun to explore its role in the CNS. For example, Miller et al. (2014) first reported enriched expression of Lgr5 in the olfactory bulb (OB) and the cerebellum. Upon closer inspection, they found that cerebral granule neurons expressed Lgr5 and R-spondin 1 during their Wnt-dependent maturation phase. Previous transcriptomic network analyses showed that Lgr5 is commonly associated with genes related to neuronal development, function, and projection (Song et al., 2015). Together, these pieces of evi- dence suggest that Lgr5 has important, unique roles outside of epithelial stem cell niches.

Yu et al. (2017) present data that substantiates a novel role for Lgr5 in mature $\mathrm{OB}$ neurons. They find that the pattern of expression of Lgr5 in the OB is similar to that of a previous study (Miller et al., 2014). They show that Lgr $5^{+}$cells in the embryonic, neonatal, and adult $\mathrm{OB}$ do not colabel with Sox 2 and Nestin, two canonical neuronal stem cell markers. They also show that Lgr ${ }^{+}$cells do not colabel with Ki67 or incorporate BrdU, indicating that they are not actively proliferating. To demonstrate that $\operatorname{Lgr} 5^{+} \mathrm{OB}$ neurons do not give rise to progeny, the authors perform lineage-tracing experiments using their Lgr5-EGFP-cre/ERT2 mouse crossed with a Td-tomato reporter line (their Fig. $3 A-D)$. Briefly, upon exposure to tamoxifen, Lgr5-EGFP cells will be labeled with TdTomato and, because this manipulation is genetic, putative progeny will also be labeled with TdTomato. Their results indicate that, $90 \mathrm{~d}$ after tamoxifen treatment, all TdTomato ${ }^{+}$(progeny) cells are also $\mathrm{EGFP}^{+}$, suggesting that the Lgr5$\mathrm{EGFP}^{+} / \mathrm{TdT}_{\text {Tomato }}{ }^{+}$population is a static, terminally differentiated cell population. Together, these pieces of evidence suggest that Lgr ${ }^{+}$cells are not stem cells in the OB. 
The authors then characterize Lgr5$\mathrm{EGFP}^{+}$cells by determining what other neuronal markers they express and conclude that that Lgr5-EGFP ${ }^{+}$cells comprise a heterogeneous set of mostly dopaminergic neurons scattered across different regions of the OB. For example, they report that nearly $50 \%$ of Lgr5-EGFP ${ }^{+}$cells express tyrosine hydroxylase (TH), a dopaminergic neuronal marker. Of these cells, nearly all express GAD67, whereas a smaller number express GAD65 (both are GABAergic markers). Last, they perform in situ hybridization and identify a glutamatergic neuronal population (their Fig. 4). Despite the heterogeneity of Lgr5 ${ }^{+}$cells, the authors emphasize that Lgr5 is preferentially expressed in $\mathrm{TH}^{+}$dopaminergic neurons. This is further supported by the fact that $\operatorname{Lgr} 5^{+}$is not expressed in calbinin- or calretinin-positive cells despite these proteins being expressed in $37 \%$ of juxtaglomerular neurons.

These differences in marker expression are reflected in functional assessments with a robust stratification in electrophysiological properties of $\mathrm{Lgr}^{+}$neurons (their Fig. 8). For example, patch-clamp recording of Lgr5-EGFP ${ }^{+}$glomerular layer neurons induced tonic, bursting, delayed-firing, or single-spike firing patterns. Curiously, these firing patterns were almost identical to those of Lgr5-EGFP ${ }^{-}$cells; one major difference between Lgr5-EGFP ${ }^{+}$and Lgrf5$\mathrm{EGFP}^{-}$cells is in their spike amplitudes, with Lgr5-EGFP ${ }^{+}$cells displaying a twofold increase in amplitude. In addition, Lgr5$\mathrm{EGFP}^{+}$cells show spontaneous EPSCs (sEPSCs), which suggests full participation and integration into the $\mathrm{OB}$ neural network.

Last, the authors explore the role of R-spondin 3, an Lgr5 ligand that has been shown to bind to Lgr5 in other settings (de Lau et al., 2011). After confirming that $\mathrm{R}$-spondin 3 is expressed in the $\mathrm{OB}$, the authors determine how R-spondin 3 affected the electrophysiological characteristics of Lgr5-EGFP $^{+}$cells. Patch-clamp recording of OB slices bathed with R-spondin 3 had no significant effects on resting membrane potential, sEPSC frequency, or sEPSC amplitude. The authors posit that the electrophysiological properties of these cells might be under chronic regulation by R-spondin 3 and this might have prevented the observation of effects of acute exposure. Given the earlier discussion of Lgr5 in supporting neuronal maturation, it is not surprising that acute exposure to R-spondin 3 does not affect electrophysiological properties. Instead, this piece of evidence strengthens the argument that
Lgr5 recruits Wnt signaling for processes related to cell maturation. If genetic deletion of R-spondin ligands and rescue with extracellular R-spondin resulted in minimal electrophysiological changes, then this idea would stand more strongly.

One of the most compelling elements of this study is the demonstration that Lgr5-EGFP $^{+}$expression is absent from the rostral migratory stream (RMS) and subventricular zone (SVZ), two hot spots of adult neurogenesis. A tightly regulated population of heterogeneous precursors from the SVZ migrate to the OB via the RMS (Whitman and Greer, 2009). Accordingly, the $\mathrm{OB}$ continually receives newly born neurons and integrates a portion of these into its circuits (Lledo, Alonso and Grubb, 2006). The maturation, integration, and survival of newly born neurons depends partly on experience (Yamaguchi and Mori, 2005). In Yu et al. (2017), the authors find that Lgr5-EGFP ${ }^{+}$is expressed in cells of all maturation stages and the authors make the point that Lgr5 expression must begin after neural precursors reach the $\mathrm{OB}$. The authors show that sensory deprivation leads to an accumulation of immature Lgr5$\mathrm{EGFP}^{+}$neurons and it would be interesting to demonstrate whether knocking out Lgr5 from the $\mathrm{OB}$ phenocopies the consequences of sensory deprivation.

These data raise the possibility that Lgr5 and R-spondin 3 play a role in the maturation, integration, or survival of $\mathrm{OB}$ neurons via the potentiation of Wnt signaling. For example, CamK4 is a Wnt target gene and promotes neuronal survival (Hödar et al., 2010). To further support this mechanism, additional experiments would be needed. For example, is the expression of Lgr5 correlated with maturation stages? That is, do immature Lgr5 ${ }^{+}$ OB neurons express more Lgr5 than mature Lgr5 ${ }^{+} \mathrm{OB}$ neurons? This could be achieved via FACS sorting on the basis of EGFP and more meticulous analysis of high and low Lgr5-expressing cells. Such an assay would be reminiscent of the study performed by Walker et al. (2007) finding that doublecortin-positive cells (a marker commonly used to represent neuronally committed cells) segregated into either neuronally committed or multipotent precursors. This emphasizes the possibility that various expression levels of Lgr5 might result in different neuronal properties.

In sum, the findings of Yu et al. (2017) significantly advance the study of Wnt signaling in the nervous system and open the possibility for a deeper mechanistic understanding of the relationship between neural stem cell niches, Wnt signaling, and neuronal maturation. The $\mathrm{OB}$ is a uniquely positioned structure in the nervous system. For example, SGZ-derived neurons must migrate to the $\mathrm{OB}$, whereas SVZ-derived neurons migrate very little (Whitman and Greer, 2009). In addition to receiving migrating neurons, the $\mathrm{OB}$ must also contend with the turnover of neurons in the peripheral olfactory epithelium, all while retaining an intact sense of smell (Whitman and Greer, 2009). This suggests that the sculpting of neural networks in the $\mathrm{OB}$ might be more complex than that of the hippocampus. Could the lack of expression of Lgr5 in the hippocampus reflect the dynamic differences between the hippocampus and OB? Last, whereas Wnt signaling is an important element of SGZ-induced neurogenesis (Rosso and Inestrosa, 2013), the lack of expression of Lgr5 (and therefore absence of Lgr5dependent Wnt signaling) in the SGZ suggests a biological and functional differencebetweenLgr5-dependentand-independent Wnt signaling.

\section{References}

Artegiani B, Lyubimova A, Muraro M, van Es JH, van Oudenaarden A, Clevers H (2017) A single-cell RNA sequencing study reveals cellular and molecular dynamics of the hippocampal neurogenic niche. Cell Rep 21: 3271-3284. CrossRef Medline

Barker N, Huch M, Kujala P, van de Wetering M, Snippert HJ, van Es JH, Sato T, Stange DE, Begthel $\mathrm{H}$, van den Born M, Danenberg E, van den Brink S, Korving J, Abo A, Peters PJ, Wright N, Poulsom R, Clevers H (2010) Lgr5+ve stem cells drive self-renewal in the stomach and build long-lived gastric units in vitro. Cell Stem Cell 6:25-36. CrossRef Medline

Chiva-Blanch G, Suades R, Crespo J, Peña E, Padró T, Jiménez-Xarrié E, Martí-Fàbregas J, Badimon L (2016) Microparticle shedding from neural progenitor cells and vascular compartment cells is increased in ischemic stroke. PLoS One 11:e0148176. CrossRef Medline

de Lau W, Barker N, Low TY, Koo BK, Li VS, Teunissen H, Kujala P, Haegebarth A, Peters PJ, van de Wetering M, Stange DE, van Es JE, Guardavaccaro D, Schasfoort RB, Mohri Y, Nishimori K, Mohammed S, Heck AJ, Clevers H (2011) Lgr5 homologues associate with wnt receptors and mediate R-spondin signaling. Nature 476:293-297. CrossRef Medline

de Lau W, Peng WC, Gros P, Clevers H (2014) The R-spondin/Lgr5/Rnf43 module: regulator of wnt signal strength the R-spondin/Lgr5/Rnf43 module: regulator of wnt signal strength. Genes Dev 28:305-316. CrossRef Medline

Hödar C, Assar R, Colombres M, Aravena A, Pavez L, González M, Martínez S, Inestrosa NC, Maass A (2010) Genome-wide identification of new Wnt/beta-catenin target genes in the human genome using CART method. BMC Genomics 11:348. CrossRef Medline

Koo BK, Clevers H (2014) Stem cells marked by the r-spondin receptor LGR5. Gastroenterology 147:289-302. CrossRef Medline 
Lledo PM, Alonso M, Grubb MS (2006) Adult neurogenesis and functional plasticity in neuronal circuits. Nat Rev Neurosci 7:179-193. CrossRef Medline

Li Z (2013) CD133: A stem cell biomarker and beyond. Exp Hematol Oncol 2:1. CrossRef Medline

Miller TE, Wang J, Sukhdeo K, Horbinski C, Tesar PJ, Wechsler-Reya RJ, Rich JN (2014) Lgr5 marks post-mitotic, lineage restricted cerebellar granule neurons during postnatal development. PLoS One 9:e114433. CrossRef Medline

Rosso SB, Inestrosa NC (2013) WNT signaling in neuronal maturation and synaptogenesis. Front Cell Neurosci 7:103. CrossRef Medline Sei Y, Lu X, Liou A, Zhao X, Wank SA (2011) A stem cell marker-expressing subset of enteroendocrine cells resides at the crypt base in the small intestine. Am J Physiol Gastrointest Liver Physiol 300:G345-G356. CrossRef Medline

Song SJ, Mao XG, Wang C, Han AG, Yan M, Xue XY (2015) LGR5/GPR49 is implicated in motor neuron specification in nervous system. Neurosci Lett 584:135-140. CrossRef Medline Sun Y, Kong W, Falk A, Hu J, Zhou L, Pollard S, Smith A (2009) C0D133 (Prominin) negative human neural stem cells are clonogenic and tripotent. PLoS One 4:e5498. CrossRef Medline

Walker TL, Yasuda T, Adams DJ, Bartlett PF (2007) The doublecortin-expressing population in the developing and adult brain contains multipotential precursors in addition to neuronal-lineage cells. J Neurosci 27:37343742. CrossRef Medline

Whitman MC, Greer CA (2009) Adult neurogenesis and the olfactory system. Prog Neurobiol 89:162-175. CrossRef Medline

Yamaguchi M, Mori K (2005) Critical period for sensory experience-dependent survival of newly generated granule cells in the adult mouse olfactory bulb. Proc Natl Acad Sci U S A 102:96979702. CrossRef Medline

Yu Y, Moberly AH, Bhattarai JP, Duan C, Zheng Q, Li F, Huang H, Olson W, Luo W, Wen T, Yu H, Ma M (2017) The stem cell marker Lgr5 defines a subset of post-mitotic neurons in the olfactory bulb. J Neurosci 37:94039414. CrossRef Medline 